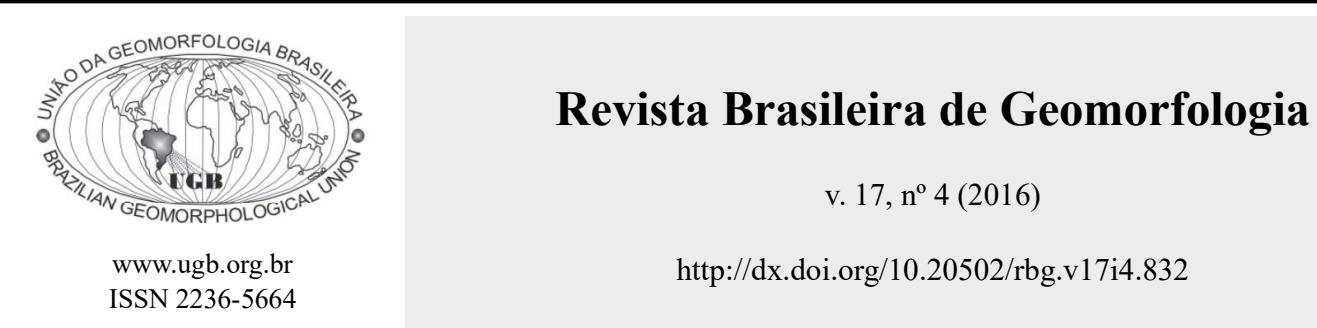

\title{
FACIOLOGIA E EVOLUÇÃO DOS DEPÓSITOS EÓLICOS COSTEIROS DO OESTE DO CEARÁ (BRASIL) NO HOLOCENO TARDIO
}

\section{FACIOLOGY AND EVOLUTION OF EOLIAN COASTAL DEPOSITS OF WESTERN CEARÁ STATE (BRAZIL) DURING THE LATE HOLOCENE}

\author{
Áquila Ferreira Mesquita \\ Departamento de Geologia, Universidade Federal do Ceará \\ Av. Humberto Monte, s/n, Campus do Pici, Bloco 913, Fortaleza, Ceará. CEP 60020-181. Brasil \\ Email:aq.fmesquita@gmail.com
}

Wellington Ferreira da Silva Filho

Departamento de Geologia, Universidade Federal do Ceará Av. Humberto Monte, s/n, Campus do Pici, Bloco 913, Fortaleza, Ceará. CEP 60020-181. Brasil Email:welfer@ufc.br

Cynthia Romariz Duarte

Departamento de Geologia, Universidade Federal do Ceará Av. Humberto Monte, s/n, Campus do Pici, Bloco 913, Fortaleza, Ceará. CEP 60020-181. Brasil Email: cynthia.duarte@ufc.br

Francisco Hilário Rego Bezerra Departamento de Geologia, Universidade Federal do Rio Grande do Norte Campus Universitário s/n, Lagoa Nova, Natal, Rio Grande do Norte. CEP 58078-970. Brasil Email: bezerrafh@geologia.ufrn.br

David Lino Vasconcelos

Departamento de Geologia, Universidade Federal do Rio Grande do Norte Campus Universitário s/n, Lagoa Nova, Natal, Rio Grande do Norte. CEP 58078-970. Brasil Email: davidgeologia2006.1@hotmail.com

Joel Pedrosa Sousa

Departamento de Geologia, Universidade Federal do Ceará Av. Humberto Monte, s/n, Campus do Pici, Bloco 913, Fortaleza, Ceará. CEP 60020-181. Brasil Email: joelppedrosa1@gmail.com

Informações sobre o Artigo

Recebido (Received): 04/09/2015

Aceito (Accepted): $16 / 09 / 2016$

\section{Resumo:}

Este estudo teve como objetivo caracterizar a morfologia e a evolução dos depósitos costeiros do oeste do Ceará, reconstituindo a paleogeografia da área, em associação com o comportamento do nível médio do mar no Holoceno Tardio. Por meio da análise faciológica e petrográfica, foram identificados cinco fácies sedimentares e suas formas deposicionais 


\section{Palavras-chave:}

Eolianitos; Arenitos de Praia; Nível do Mar.

\section{Keywords:}

Eolianites; beachrocks and Sea Level.

originais: arenito grosso com níveis conglomeráticos e estratificação planoparalela inclinada (face de praia); arenito médio com estratificação cruzada de baixo ângulo (dunas frontais), por vezes obliteradas por rizolitos (dunas frontais vegetadas); arenito médio com estratificação cruzada festonada (base de dunas barcanóides); arenito médio com estratificação cruzada e superfícies de truncamento em "Z" (extensões linear e associadas a dunas barcanóides). Os arenitos grossos correspondem a rochas de praia, sotopostas por eolianitos (fácies restantes) na forma de yardangs subparalelos à direção de vento efetivo atual (NE-SW). As feições-chave são: contato entre rochas de praia e eolianitos (paleolimite face de praia/pós-praia) cerca de $2 \mathrm{~m}$ acima do nível máximo da preamar atual; afloramentos de arenitos de praia no interior do continente, sucessão de cimentação marinha freática para vadosa nas rochas de praia e vales incisos em eolianitos/rochas de praia. Essas evidências indicam que os depósitos eólicos foram gerados durante uma ascensão relativa de nível médio do mar, quando houve maior disponibilidade de sedimentos para a alimentação dos campos de dunas, sendo cimentados e entalhados por cursos d'água durante o subsequente rebaixamento relativo.

\begin{abstract}
:
This study aimed to characterize the morphology and evolution of coastal deposits in western Ceará state based on the variation of the sea level in the Late Holocene, thus reconstructing the paleogeography of the area. Based on the petrography and facies analysis, five sedimentary facies and their original depositional forms (facies associations) have been identified as follows: coarse-grained sandstone with layers of conglomerate and inclined planar stratification (foreshore); medium sandstone with low-angle cross-stratification (foredunes), sometimes obliterated by rhizoliths (vegetated foredunes); medium sandstone with trough cross-stratification (the base of barchanoid dunes); medium sandstone with crossstratification; and Z-shaped truncation surfaces (linear extensions associated with barchanoid dunes). Coarse-grained sandstones correspond to beachrocks, which were overlaid by eolianites (remaining facies), in the form of yardangs subparallel to the direction of present effective wind (NE-SW). The key features are contact between beachrocks and eolianites (a former foreshore/backshore limit) about $2.0 \mathrm{~m}$ above the maximum of present high tide; inland outcrops of beachrock; succession of phreatic to vadose marine cementation in the beachrocks; and eolianite/beachrock incised valleys. All this evidence indicates that the eolian deposits were generated during a relative rise in the sea level, when there was greater availability of sediment to supply the dune fields, being cemented and locally eroded by streams during the subsequent relative fall.
\end{abstract}

\section{Introdução}

A costa setentrional do Brasil é dominada, principalmente, por processos eólicos que levaram à acumulação e à deflação de sedimentos siliciclásticos e à construção de campos de dunas durante o Holoceno. Nessa época, os processos morfodinâmicos costeiros (HESP, 2013), flutuações climáticas (MEIRELES et al., 2005; TSOAR et al., 2009) e regime de ventos (HESP et al., 2009; HESP, 2013) favoreceram a instalação de diversas gerações de dunas.

Os processos eólicos ocorrem preferencialmente em regiões áridas/ semiáridas, onde as baixas pre- cipitações resultam em um substrato seco, aliado à cobertura vegetal relativamente escassa, que aumenta a capacidade do vento no transporte de material particulado. Subordinadamente, os processos eólicos também ocorrem em ambientes úmidos onde há abundante disponibilidade de sedimentos e a velocidade do vento é suficiente para a deflação e transporte (PYE, 1983; MOUNTNEY \& JAGGER, 2004).

São identificadas quatro principais gerações de dunas ao longo da região costeira do Ceará a partir de suas relações de contato (MAIA, 1998; BANDRÃO, 1995). A primeira geração envolve paleodunas que, 
segundo Brandão (1995), encontram-se em contato direto com a Formação Barreiras constituídas por areias bem selecionadas, de granulação fina a média, com tons amarelados, alaranjados e acinzentados, de composição quartzosa e, em menor abundância, quartzo-feldspática. Normalmente, são sedimentos inconsolidados, pobremente compactados e que podem apresentar estratificações plano-paralelas e cruzadas. Apresentam níveis pelíticos de espessuras centimétricas intercalados com pacote arenoso e que podem ser interpretados como depósitos de ambiente úmido correspondente a áreas baixas de interdunas. A segunda geração é composta por dunas parabólicas de areias quartzosas de granulação média a fina, inconsolidadas. São bastante comuns na costa cearense e apresentam-se inativas, capeadas por vegetação de baixo porte. Os eolianitos representam a terceira geração de dunas localizadas na faixa costeira oeste do Ceará e são formados por pacotes de arenitos quartzosos cimentados por carbonato de cálcio e com bioclastos carbonáticos e sinais de bioturbação. Segundo Carvalho et al. (2008), a litificação dessa unidade ocasionou sua preservação ao longo do tempo, de forma que a ação erosiva do vento e da chuva contribuíram para a modelagem em relevo ruiniforme com formas alongadas aproximadamente E-W (yardangs) e tabulares (zeugen). A quarta geração de dunas é representada pelos campos de dunas atuais, compostos, principalmente, por dunas barcanas, parabólicas e frontais, ativas ao longo do litoral do estado do Ceará (BEZERRA, 2009; MAIA, 1998 e BRANDÃO, 1995).

Os depósitos de eolianitos exibem estruturas sindeposicionais bem evidentes, como estratificações cruzadas de grande porte e que representam uma notória unidade litoestratigráfica no litoral brasileiro. Essa unidade fornece importantes informações sobre o sistema deposicional eólico e as condições climáticas e morfodinâmicas do ambiente costeiro existentes à época de sua formação (CARVALHO et al., 2008).

O modelo proposto por Maia (1998), apesar de pioneiro e de ser extensamente utilizado para trabalhos desenvolvidos na região litorânea do Ceará, não aborda as características faciológicas, evolutivas e genéticas entre as gerações de dunas descritas e os depósitos correlacionados. Apesar de sua representatividade no ponto de vista geológico/geomorfológico na compartimentação da zona costeira cearense, os eolianitos ainda são pouco estudados, especialmente em sua relação às rochas de praia adjacentes. Portanto, o presente trabalho apresenta resultados de pesquisas realizadas na área sob o ponto de vista estratigráfico e que objetivou caracterizar a morfologia e a evolução dos depósitos costeiros do oeste do Ceará, reconstruindo a paleogeografia da área em associação ao comportamento do nível do mar no Holoceno.

Estudos sobre as variações do nível relativo do mar na costa setentrional do Brasil são escassos e pontuais, com curvas bem definidas para o litoral do Rio Grande do Norte (BEZERRA et al., 2003; CALDAS et al., 2006), e para os estados do Pará e do Maranhão (COHEN et al., 2005; BEHLING et al., 2001; BEHLING \& COSTA, 2001). Além do posicionamento geográfico de aquisição dessas curvas, a ambiguidade entre ambas e o contexto neotectônico do setor estudado (BEZERRA \& VITA-FINZI, 2000, BEZERRA, et al., 2005; SILVAFILHO et al., 2007) impede que uma correlação adequada seja possível para o Ceará. Nesse contexto, o presente trabalho apresenta informações qualitativas do comportamento do nível do mar no Holoceno à luz dos depósitos e das formas de relevo encontrados.

\section{Características da área de estudo}

A área de estudo encontra-se na costa oeste do Ceará, aproximadamente, a $130 \mathrm{~km}$ de Fortaleza (Figura 1), entre os municípios de Itarema e Trairi. $\mathrm{O}$ arcabouço geológico Cenozoico é composto por depósitos sedimentares da Formação Barreiras (Mio-Plioceno) (ARAI, 2006) e depósitos quaternários aluviais e eólico-praias litorâneos. A definição da área de estudo foi estabelecida de forma a incluir os principais afloramentos de eolianitos a leste da desembocadura do rio Acaraú.

A compartimentação do relevo desse setor é constituída por três principais domínios geomorfológicos: Planície Litorânea, Glacis Pré-Litorâneos dissecados em interflúvios tabulares e Maciços Residuais, cujos limites são estabelecidos com base na homogeneidade das formas de relevo, posicionamento altimétrico, estrutura geológica, atividade tectônica, assim como nas características do solo e da vegetação (MARIA, 2007). Dentro desses domínios, podem ser encontradas unidades e feições morfológicas como faixa de praia, dunas móveis e fixas, yardangs, planície fluvio-marinha e tabuleiros pré-litorâneos. (SOARES, 1998). 


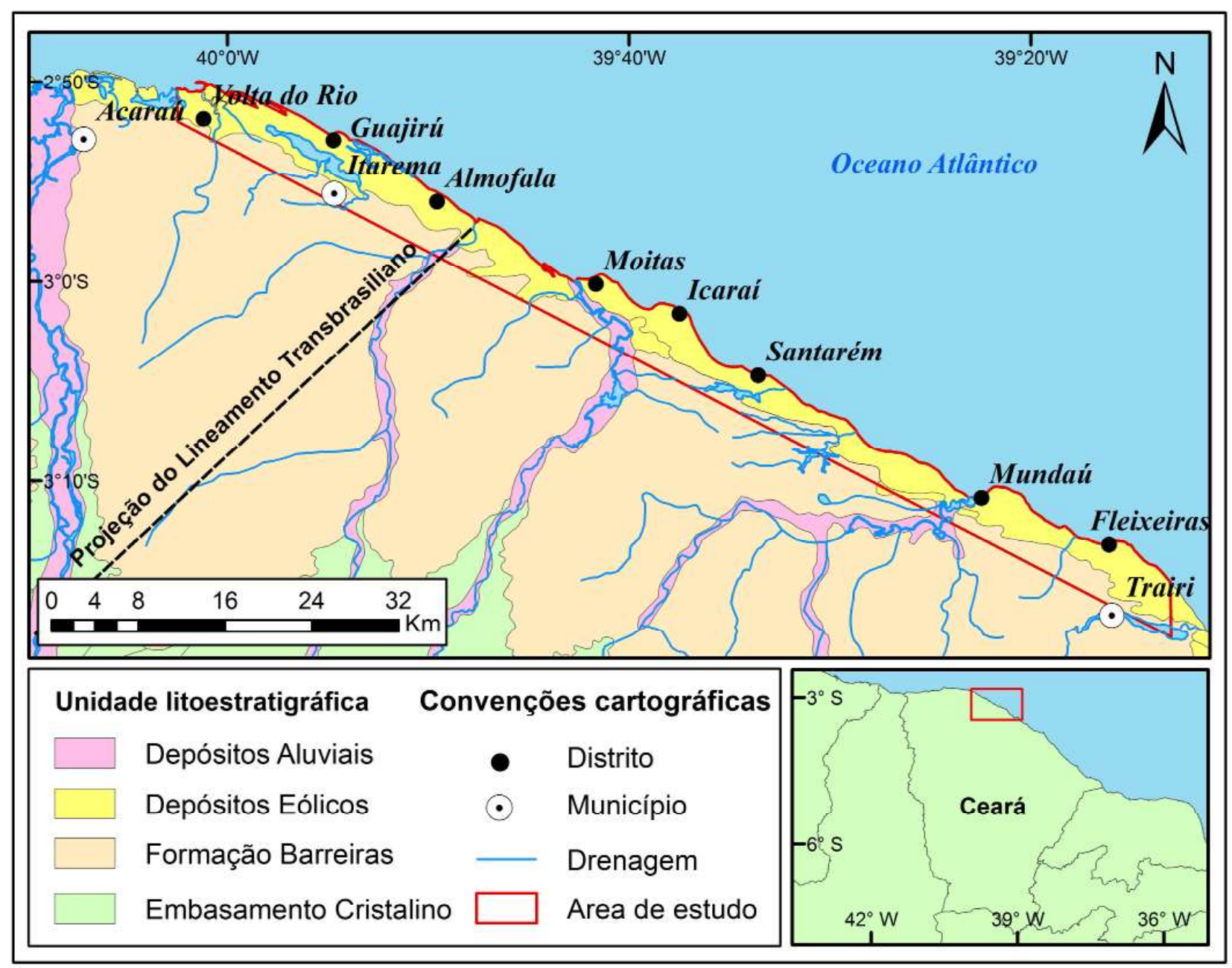

Figura 1 - Mapa de situação geológica da área de estudo. Projeção: UTM,WGS 84, Zona 24 Sul.

Esse setor litorâneo apresenta praias dissipativas, com regime de mesomarés dominado por ondas com altura média de 0,56 metros. As marés são de caráter semidiurno e possuem amplitude média, em maré de sizígia, de $-0,20 \mathrm{~m}$ na baixa-mar a 3,2 $\mathrm{m}$ na preamar com relação ao nível médio do mar atual (DHN, 2012). Os padrões de ondas são predominantemente do tipo sea, com os maiores registros de entradas de ondas do tipo swell nos meses de março a maio. Essa distribuição está relacionada ao deslocamento da zona de convergência intertropical para sul da Linha do Equador durante os primeiros meses do ano (AGUIAR et al., 2013). Por sua vez, o regime eólico é marcado pela ação dos ventos alísios principalmente de SE, mais ativos durante o período de julho a dezembro, com uma velocidade média da ordem de $8 \mathrm{~m} / \mathrm{s}$ (CLAUDINO SALES, 1993; MAIA, 1998). Os ventos alísios de NE têm menor velocidade, da ordem média de $3,5 \mathrm{~m} / \mathrm{s}$, e atuam, sobretudo, durante janeiro a junho. Ao longo de todo o ano, ocorre ainda a atuação de alísios de E (CLAUDINO SALES et al., 2006).

\section{Materiais e métodos}

Foram descritas seções geológicas e colunares com o objetivo de caracterizar as possíveis sucessões de fácies sedimentares presentes. Essas seções foram niveladas em relação ao alcance máximo do espraiamento da maré com o auxílio de um nível a laser FG-L3 (Freiberger Prazisionsmechanik), um receptor Apache Cyclone Laser Detector e um GPS de navegação Garmin etrex (datum horizontal WGS-84), com a precisão vertical variável entre 5 a 8 metros. Os dados coletados foram relacionados em relação às medidas do maréografo do Terminal Portuário do Pecém, localizado cerca de 50 $\mathrm{km}$ a leste da área de estudo, fornecido gratuitamente 
pela Marinha do Brasil por meio de uma tábua de marés (DHN, 2012).

Com o objetivo de caracterizar petrograficamente as fácies sedimentares, foram utilizadas técnicas de impregnação de rochas sedimentares com resina "epoxy" para a confecção de lâminas delgadas. O material coletado é extremamente friável, impossibilitando a aplicação da técnica em fácies com baixo grau de cimentação. Essa técnica foi originalmente concebida para amostras de solos inalteradas e consiste na imersão da amostra em uma solução de 50\% de araldite (XGY -1109), 5\% de endurecedor (HY-951) e $45 \% \pm 5 \%$ de acetona. Após esse procedimento, a amostra e a solução são colocadas em um dissecador de vidro acoplado a uma bomba a vácuo por aproximadamente 24 horas (PAULA et al., 1991). Uma vez endurecidas as amostras, foram confeccionadas as seções delgadas.

\section{Aspectos faciológicos}

As análises faciológicas de rochas de praia e de eolianitos do litoral oeste cearense foram realizadas para se obter uma correlação entre a dinâmica e o contexto paleoambiental que originaram os depósitos em estudo. Nesse intuito, foram observados alguns critérios básicos para classificação de fácies sedimentares, como geometria, litologia e arquitetura dos corpos sedimentares (SELLEY, 1970; MIALL, 1999; MOUNTNEY \& JAGGER, 2004). Estudos anteriores caracterizaram até seis fácies preliminares na área de estudo (VASCONCELOS e BARNABÉ, 2011; MESQUITA e SILVA, 2012). Nesse trabalho, uma nova distribuição de fácies e interpretação paleogeográfica são apresentadas para a caracterização e evolução dos depósitos costeiros na costa oeste do Ceará (Tabela 1):

Tabela 1: Fácies de beachrocks e eolianitos do litoral oeste cearense e sua interpretação.

\begin{tabular}{c|c|c}
\hline Código & Descrição & Interpretação \\
\hline $\mathrm{AGpi}$ & $\begin{array}{c}\text { Arenito grosso com níveis } \\
\text { conglomeráticos e estratificação plano-paralela inclinada }\end{array}$ & Face de praia \\
\hline $\mathrm{AMb}$ & Arenito médio com estratificações cruzadas de baixo ângulo & Pós-Praia - Dunas frontais \\
\hline $\mathrm{AMr}$ & $\begin{array}{c}\text { Arenito médio com estratificações cruzadas de baixo ângulo } \\
\text { obliteradas por rizoconcreções }\end{array}$ & $\begin{array}{c}\text { Pós-Praia - Dunas frontais } \\
\text { vegetadas }\end{array}$ \\
\hline $\mathrm{AMf}$ & Arenito médio com estratificação cruzada festonada & $\begin{array}{c}\text { Base de cadeias de dunas } \\
\text { barcanóides. }\end{array}$ \\
\hline $\mathrm{AMz}$ & $\begin{array}{c}\text { Arenito médio com estratificação cruzada com superfícies de } \\
\text { truncamento em “Z”. }\end{array}$ & $\begin{array}{c}\text { Extensões lineares vegetadas } \\
\text { de cadeias de dunas } \\
\text { barcanóides. }\end{array}$ \\
\hline
\end{tabular}

Fácies arenito grosso com níveis conglomeráticos e estratificação plano-paralela inclinada (AGpi)

A fácies AGpi é composta por arenitos quartzosos de granulação grossa, mal selecionados e acompanhado por $25 \%$ de bioclastos, especialmente segmentos milimétricos de Corallina officinalis. Níveis conglomeráticos também são observados, contendo cascalhos compostos predominantemente por quartzo, rodólitos, bivalves e fragmentos de rochas da Formação Barreiras. Essa unidade é organizada em pacotes com estratificação plano-paralela inclinada $\left(<15^{\circ}\right)$, de médio porte e com sentido de inclinação preferencialmente NE e NW, para o oceano (FiguraS $2 \mathrm{Ae} B$ ). Subordinadamente, podem ocorrer estratificações cruzadas acanaladas de médio porte.

A cimentação carbonática, apesar de predomi- nante, diminui verticalmente em direção ao do topo do pacote AGpi (Figura 2C). Na porção basal, os espaços intergranulares são preenchidos por duas principais gerações de cimento carbonático. A primeira geração é caracterizada por franjas de cristais prismáticos de calcita, principalmente sobre grãos de origem bioclástica. Por sua vez, a segunda geração é composta por carbonato predominantemente micrítico, anisópaco que envolvem franjas cristalinas da primeira geração, ou em pontes intergrãos (meniscos) (Figura 3). Por outro lado, o topo dessa unidade pode apresentar menor volume de cimento com espaços parcialmente preenchidos por uma única geração de cimento carbonático. O cimento ocorre, principalmente, como franjas de calcita microcristalina equante na superfície dos grãos, por vezes formando meniscos/pontes intergrãos (Figura 4). 


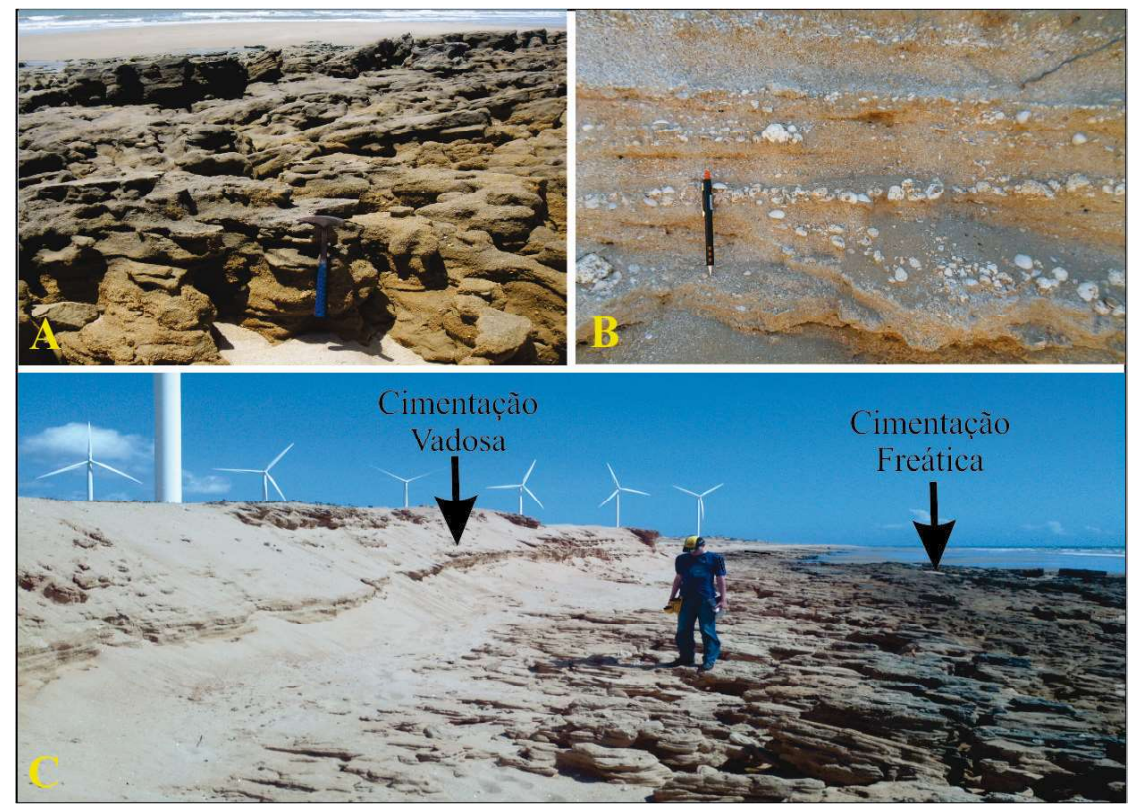

Figura 2 -A) Seção basal da fácies AGpi com estratos plano-paralelos de baixa inclinação em direção ao mar. B) Seção de topo da fácies AGpi com estratificação plano-paralela marcada por níveis cascalhosos de conchas de bivalves e rodólitos. C) Aspecto da cimentação diferencial entre as poções basais (alto grau de cimentação) e de topo (baixo grau de cimentação), com transição gradual entre ambas.
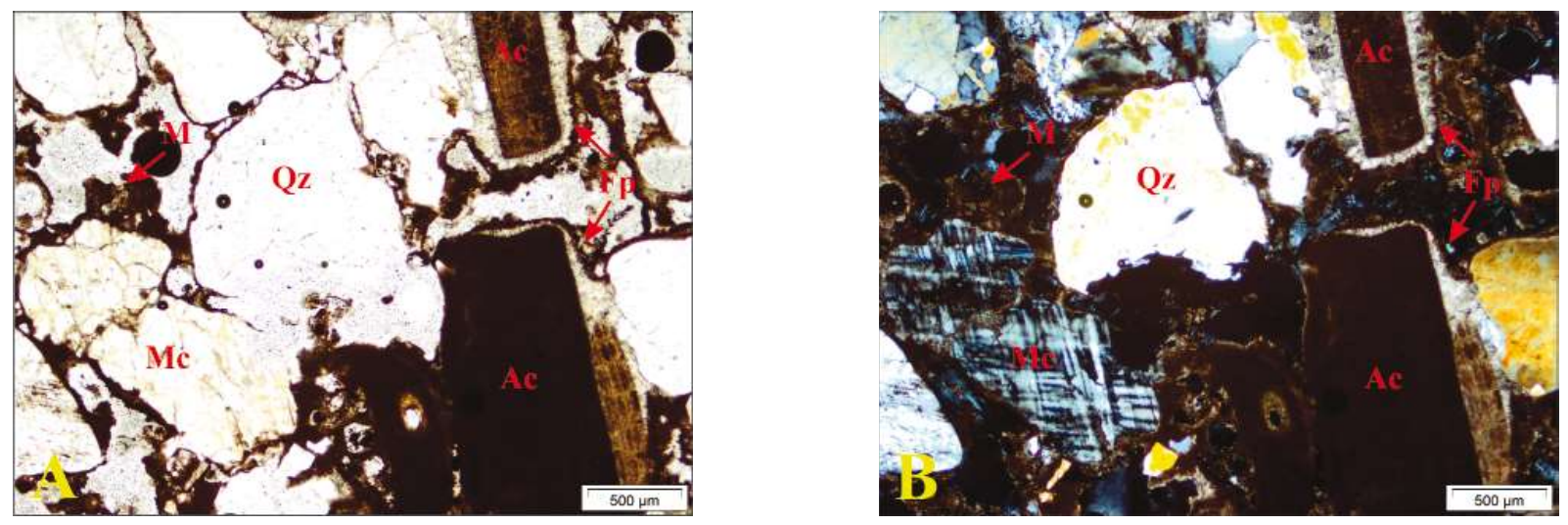

Figura 3 - Fotomicrografia da fácies AGpi, aumento de 20x, nicóis cruzados. Grãos do arcabouço: quartzo policristalino (Qz); microclina (Mc); segmento de Corallina oficinalis com estrutura reticulada típica (Ac); Cimentos: micrítico (M); franja prismática calcítica (Fp). A) Luz Natural B) Luz Polarizada
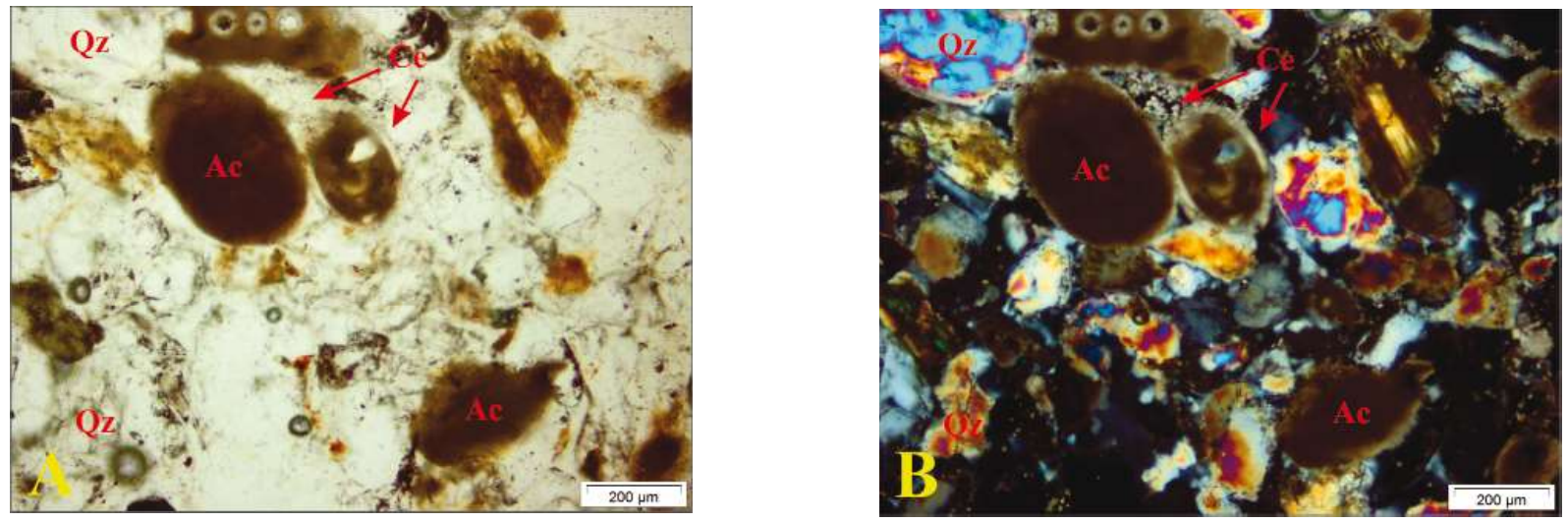

Figura 4 - Fotomicrografia da fácies AGb, aumento de 10x, nicóis cruzados. Grãos do arcabouço: quartzo policristalino (Qz); segmento de Corallina oficinalis com estrutura reticulada típica (Ac). Cimentos: franjas de calcita equante (Ce). A) Luz Natural B) Luz Polarizada. 
Em função das características litológicas, fossilíferas e estruturais, é possível que a fácies AGpi tenha sua gênese associada à zona de praia em transição para zonas proximais de pós-praia. Essa interpretação é corroborada pelas estruturas sedimentares em conjunto ao padrão de cimentação desses litossomas.

Feições como franjas cristalinas de calcita são os principais produtos de precipitação em zona freática marinha, de forma que a alta taxa de suprimento de íons carbonato e o $\mathrm{pH}$ básico nessa zona favorecem a formação de cristais de calcita ao redor de grãos preexistentes. Entretanto, a segunda geração de cimento observada, possivelmente reflete a transição desse ambiente para zona marinha vadosa, no qual a diminuição do suprimento de íons carbonato favoreceu a cimentação em forma de meniscos. É possível que essa configuração esteja relacionada à transição desses depósitos da zona de intermaré superior para zona de supramaré, respectivamente (LONGMAN, 1980; TUCKER, 1991; PEREIRA \& ROS, 2006.). A cimentação por franjas e meniscos de cristais equantes de calcita encontradas na porção superior fácies AGpi, possivelmente reflete um contexto marinho predominantemente vadoso, com interferência de água doce. A baixa taxa de suprimento de íons carbonato e as feições de dissolução na superfície de grão bioclásticos indicam a influência da percolação de fluídos meteóricos característicos de zona de supramaré (PEREIRA \& ROS, 2006; VIEIRA et al., 2007; FERREIRA JR. et al., 2011).

A sucessão de cimentos e o seu zoneamento vertical fornecem um forte indício da maior influência marinha na cimentação na base do pacote em detrimento ao topo. Essas diferenças podem ser resultantes de um soerguimento relativo do pacote ou um rebaixamento relativo do nível do mar. Essa hipótese, inclusive, é corroborada pela presença de afloramentos da fácies AGpi, aproximadamente, a $1 \mathrm{~km}$ da faixa de praia atual nas imediações da localidade de Volta do Rio.

\section{Fácies arenito médio com estratificações cruzadas de baixo ângulo (AMb)}

A fácies $\mathrm{AMb}$ é constituída por arenitos de granulação areia média, bem selecionados, com conteúdo de bioclastos variável entre $10 \mathrm{a} 15 \%$, principalmente segmentos de Corallina officinalis e apresentam corpos tabulares com estratificações cruzadas planar de baixo ângulo $\left(<15^{\circ}\right)$ com direção de mergulhos predominante para NE (Figura 5). As características texturais como seleção, granulação e arredondamento dos grãos sugerem uma origem eólica para esse depósito e suprimento sedimentar de origem marinha, visto a natureza do conteúdo bioclástico presente. Essa unidade marca a mudança do domínio praial (Fácies AGpi) para domínio continental eólico.

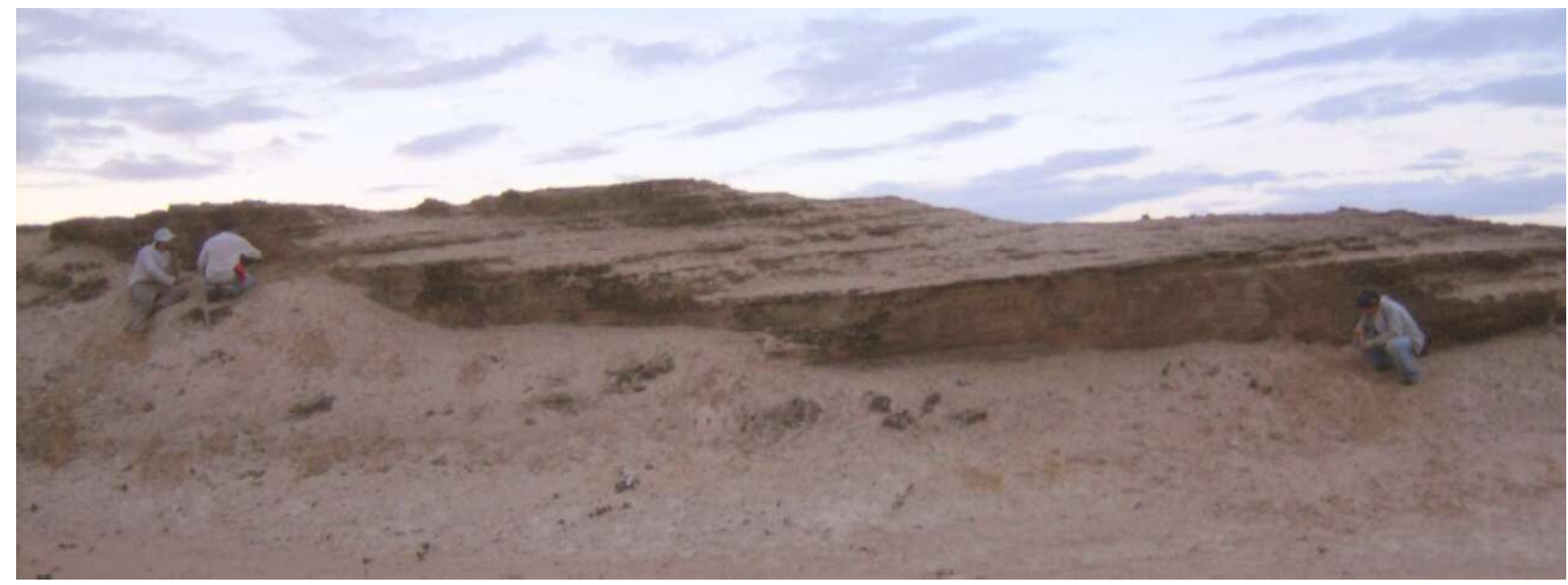

Figura 5 - Estratificações cruzadas de baixo ângulo da fácies AMb

\section{Fácies arenito médio com estratificações cruzadas de baixo ângulo obliteradas por rizólitos (AMr)}

A fácies $\mathrm{AMr}$ é composta por arenitos quartzosos de granulação média, com $15 \%$ a $20 \%$ de material bioclástico e organizada em camadas tabulares com estratificações cruzadas de baixo ângulo (Figura 6). A característica mais notória dessa fácies é a presença de icnofósseis representados por rizólitos (rizocasts e rizotubos) (Klappa et,al, 1980), obliterando, em maior 
ou menor grau, as estratificações pré-existentes.

Essa fácies é composta por grãos de areia moderadamente selecionados, com material clástico composto por quartzo e segmentos de Corallina officinalis. A fraca cimentação eodiagenética é caracterizada por pequenas pontes de calcita equante precipitada entre grãos, resultantes da dissolução de

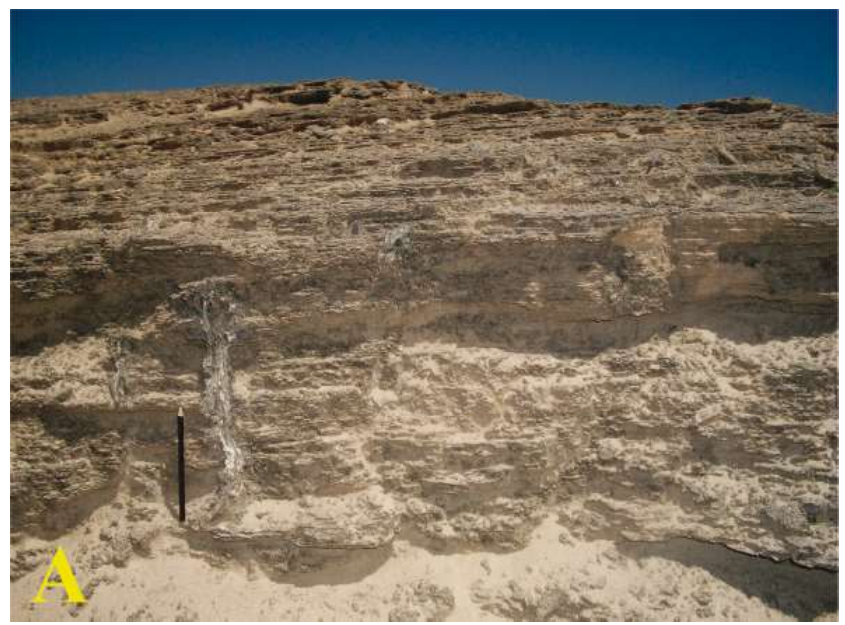

carbonato de cálcio a partir de bioclastos e precipitação ao seu redor (Figura 7). A textura equante de calcita espática no cimento, o seu pequeno volume relativo e as irregularidades na espessura (por vezes formando meniscos ou pontes entre os grãos) indicam uma baixa taxa de suprimento de íons carbonato em ambiente meteórico vadoso.

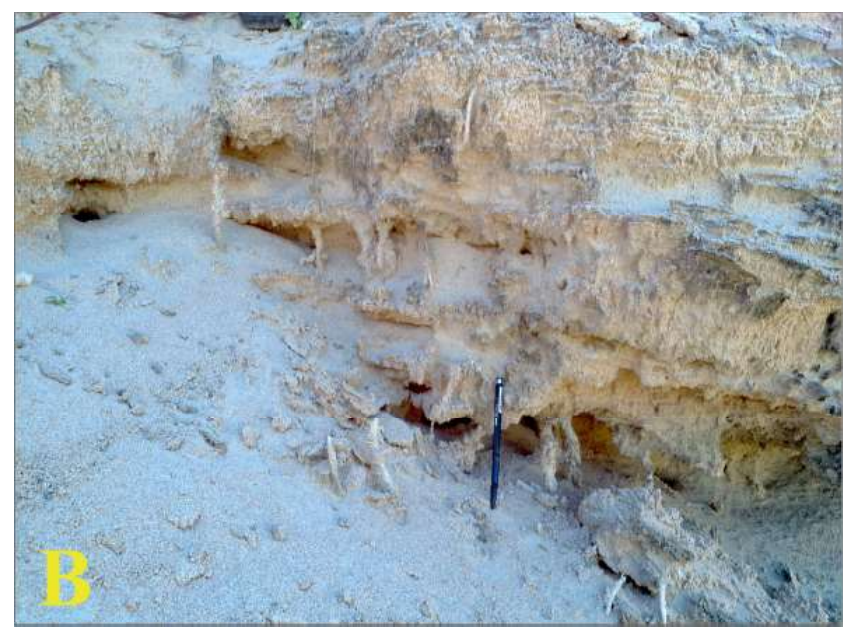

Figura 6 - A) Estratificação cruzada de baixo ângulo da fácies AMr. B) Rizolitos obliterando as estratificações pré-existentes. Vista em perfil.
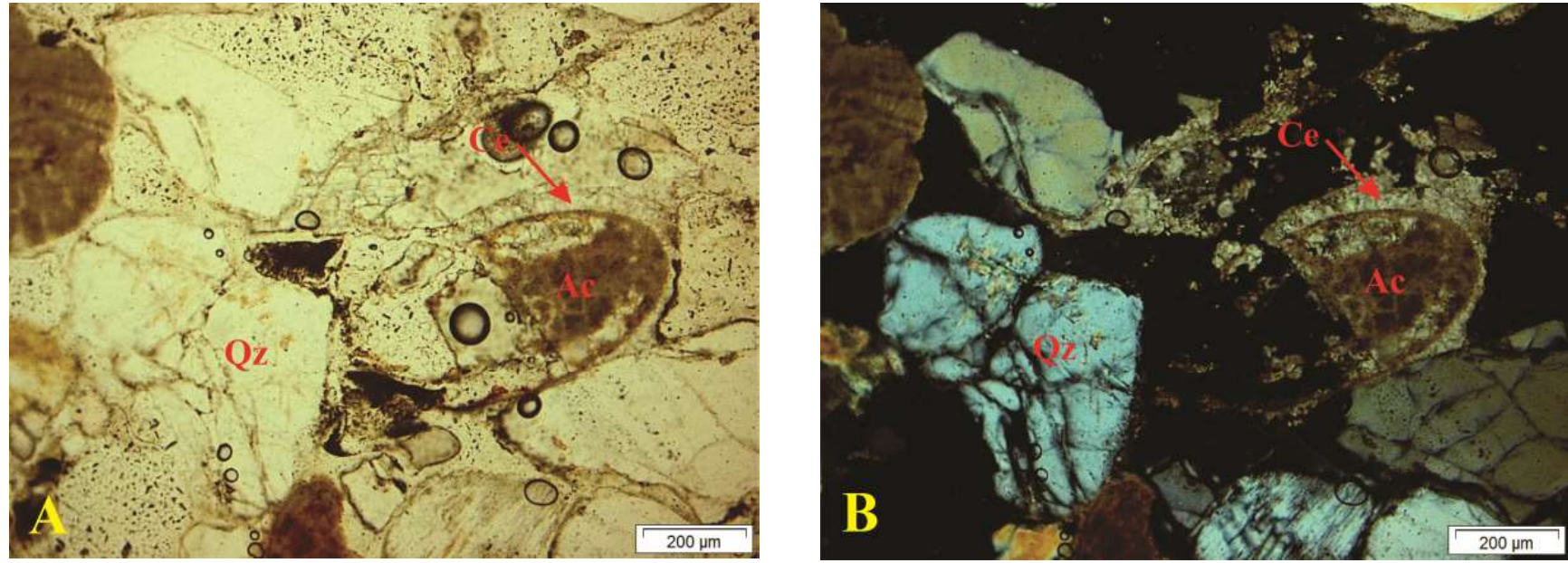

Figura 7 - Seção delgada de eolianito (Fácies AMr, aumento de 10x, nicóis cruzados. Apresenta grãos de quartzo policristalino (Qz) e algas coralinas (Colallina officinalis) (Ac). Cimentação por franja anisópaca de calcita espática equante (Ce). A) Luz natural B) Luz polarizada.

\section{Fácies arenito médio com estratificação cruzada festonada (AMf)}

Fácies AMf constitui uma unidade faciológica predominante entre as localidades de Guajirú e Fleixeiras (Figura 1)(CARVALHO et al., 2008). Essa fácies é composta de arenitos de granulação areia média de natureza quartzosa e $10 \%$ a $15 \%$ de material bioclásticos de natureza algálica (Corallina officinalis), fracamente cimentados e apresenta estratificações cruzadas festonadas, com geometria leve- mente côncava para o topo (Figura 8). Com isso, não foi possível a identificação de contatos dessa unidade com as demais devido à sua ocorrência restrita na área estudada.

\section{Fácies arenito médio com estratificação cruzada com superficie de truncamento em " $Z$ " (AMz)}

A fácies $\mathrm{AMz}$ possui expressiva distribuição na área de estudo com os principais afloramentos 
nas localidades de Santarém e Flexeiras (Figura 1). Geomorfologicamente, essa fácies ocorre dentro de numerosas cristas alinhadas paralelamente aos ventos dominantes e são formadas por deflação eólica que ocorrem em praticamente toda a área de estudo (yardangs) e apresenta-se em estratos cuneiformes (superfícies delimitantes não paralelas) de arenitos médios a grossos, quarzosos e com conteúdo bioclásti- co variando entre $10-20 \%$. As estratificações cruzadas planares com superfície de truncamento em " $Z$ " se organizam em conjuntos com caimentos alternados, em sentidos opostos, para NNW e SSW (Figura 9). Pode apresentar altos ângulos de mergulho $\left(>15^{\circ}\right)$, que são encontrados, principalmente, na região de Moitas e baixos ângulos de mergulho, como nos afloramentos em Santarém (Figura 1).

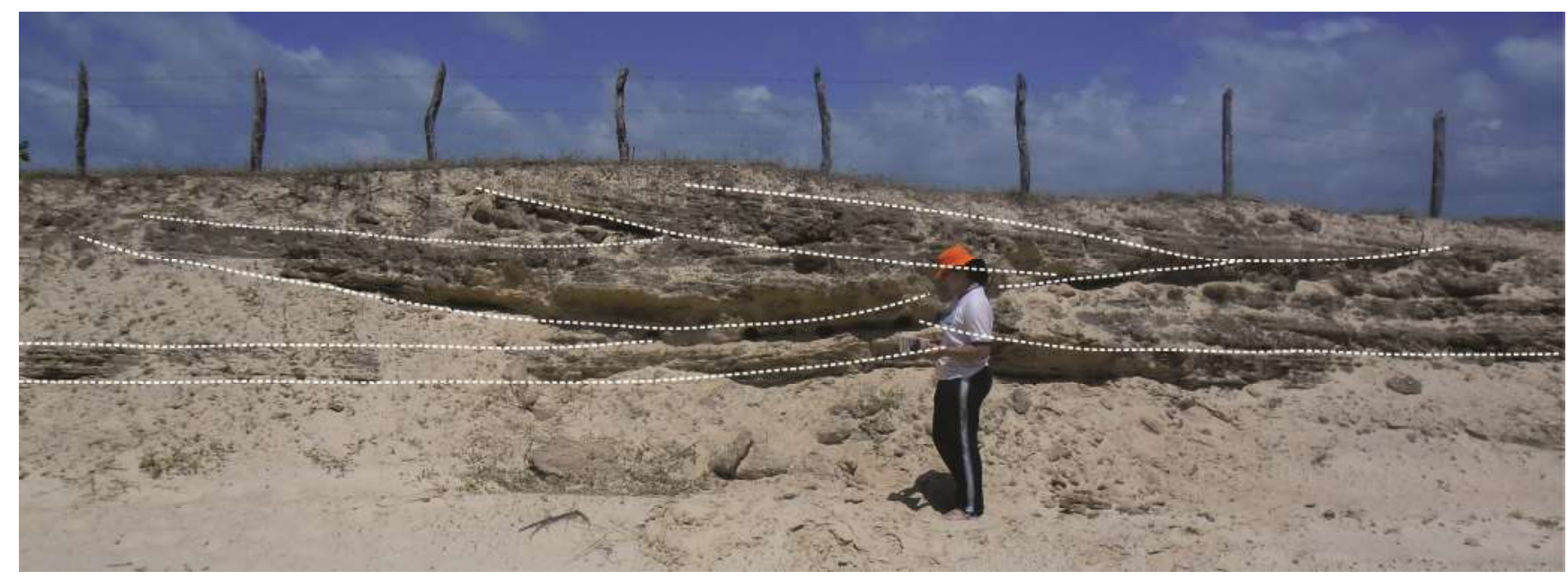

Figura 8-Estratificação cruzada festonada da fácies AMf, localidade de Guajirú.

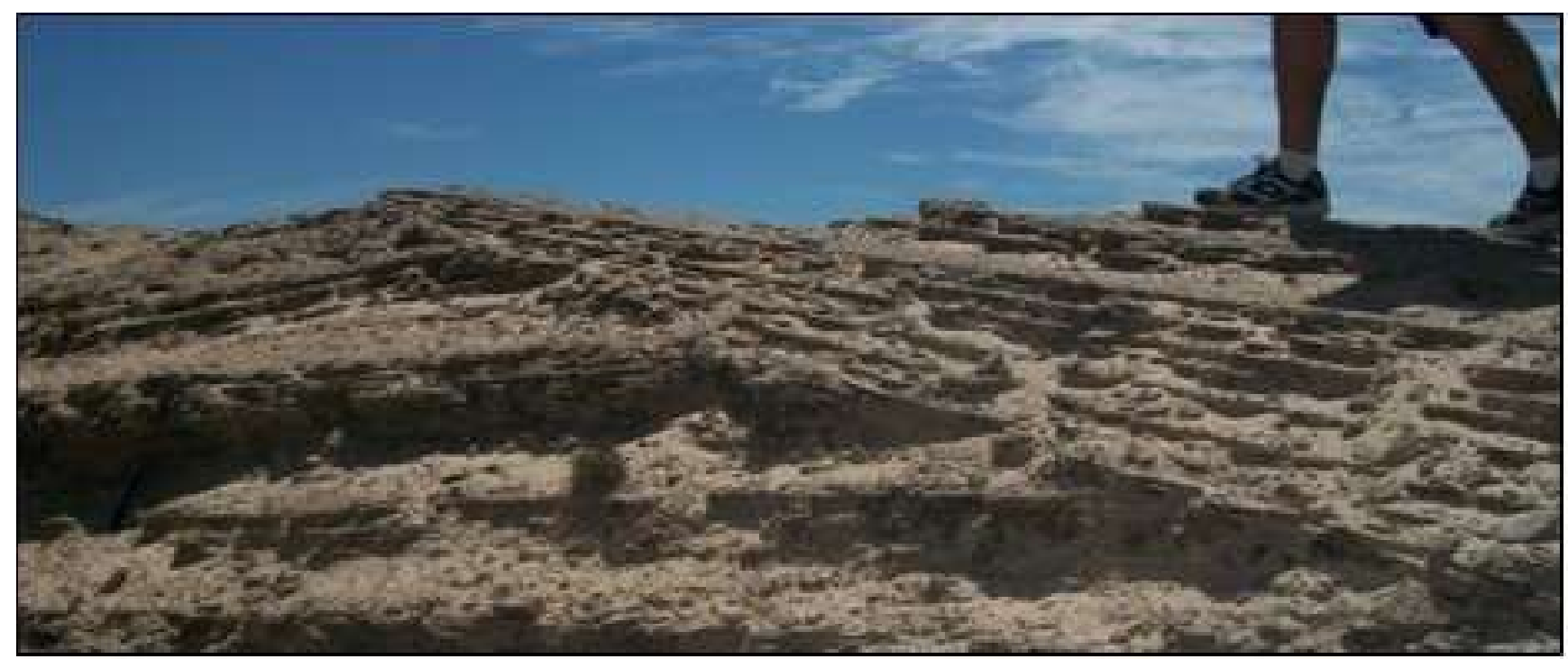

Figura 9 - Fácies AMz apresentando conjuntos de estratificações cruzadas planares com truncamentos em "Z”, sentidos de mergulho alternados para NNW e SSE. Localidade de Moitas.

\section{Associação de fácies e morfologia}

\section{Associação de fácies de faixa de praias (Fácies AGpi)}

A associação de fácies de praia é representada unicamente pela fácies AGpi e constitui a fácies de base da sucessão. A superfície limitante de topo com a fácies
$\mathrm{AMb}$ (Pós-praia) indica a mudança do ambiente deposicional praial para continental e representa o provável nível máximo de ação de ondas durante a deposição dessas unidades faciológicas. Essa superfície localiza-se entre $1,90 \mathrm{~m}$ e 2,20 $\mathrm{m}$ acima do nível máximo da preamar atual (Figura 10), o que sugere um rebaixamento 
relativo do nível do mar, na seção Almofala-Moitas-Santarém, aparentemente contínuo desde o momento de deposição até o presente. Mesmo em contexto de ondas de tempestade, a presença de afloramentos da fácies AGpi, aproximadamente a $1 \mathrm{~km}$ da linha de costa atual, auxilia na hipótese de um possível rebaixamento do nível relativo do mar para o setor
A partir da associação das estruturas internas encontradas nas fácies de eolianitos, juntamente com o modelo de fácies eólicas proposta por Giannini (2007), Martinho et al. (2006) e Giannini et al. (2011), foi possível estabelecer uma correlação entre os depósitos de eolianitos a três principais feições morfológicas: dunas frontais, cadeias de dunas barcanóides e extensões lineares.

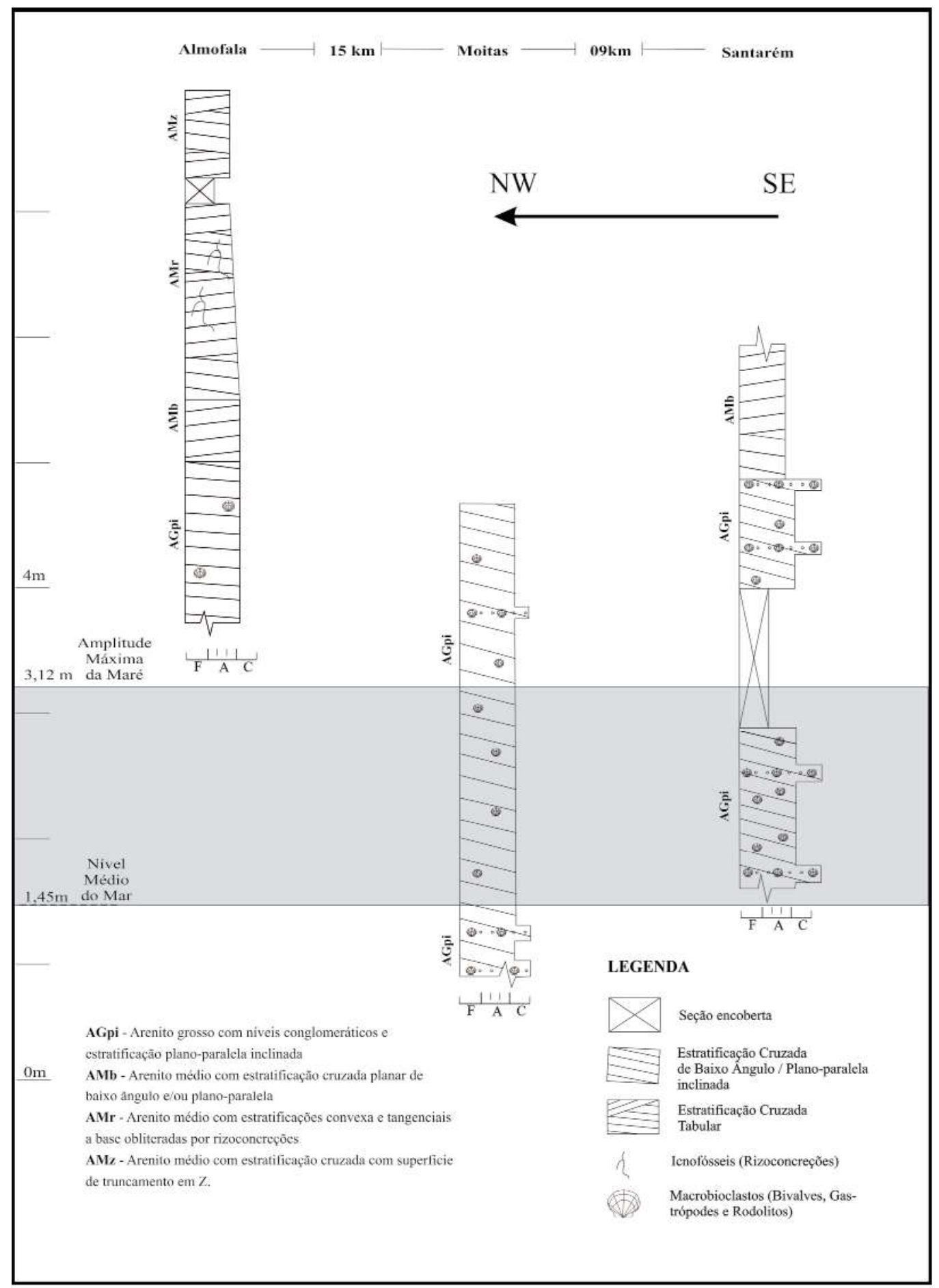

Figura 10 - Seções colunares com referência ao nível do mar atual, direção paralela à costa, de Almofala (NW) a Santarém (SE). Modificado e adaptado de Mesquita e Silva (2012). 
Associação de fácies de dunas frontais (Fácies AMb/AMr)

As dunas frontais são dunas com cristas paralelas à linha de costa, por vezes fixadas pela vegetação. São, geralmente, formadas no limite superior da ação das ondas sobre plataformas em praia progradantes, onde a colonização vegetal ajuda a reter a areia transportada pelo vento, favorecendo a formação de núcleos de protodunas (OLSON \& VAN DER MAAREL, 1989; HUNTER, 1977). Hesp (1988) estabelece quatro estágios genéticos na formação de dunas frontais baseados em sistemas eólicos no sudoeste da Austrália.

Nos estágios 1 e 2, as dunas são lateralmente contínuas e pouco vegetadas. Sua morfologia é ligeiramente assimétrica, com estratificações cruzadas com mergulhos suaves tanto a barlavento quanto a sotavento. Os estágios 3 e 4 caracterizam o tipo mais comum e são caracterizados por dunas frontais fixas por vegetação rasteira a arbustiva, com maior amplitude de onda. Neste estágio, as dunas adotam um padrão assimétrico cada vez mais distinto, fruto do aumento da cobertura vegetal em conjunto com o retrabalhamento eólico.

O estágio 5 (senil) é caracterizado pelo fim do crescimento da duna e da sua estabilização pela vegetação. No desenvolvimento das dunas frontais, a totalidade dos processos erosivos e deposicionais imprimem conjuntos distintivos de estratificações cruzadas de alto ângulo que podem ser acopladas ao estágio de evolução da duna frontal (BRISTOW et al., 2000).

Características como estratificações cruzadas de baixo ângulo $\left(<15^{\circ}\right)$, preservação de estratificações dorsais (backset), com mergulho para o mar e de topo de duna (topset), além da escassez de feições de avalanche são feições comumente encontradas em dunas desse tipo (HUNTER, 1977; HESP 1983 ,1988, 2002; BRISTOW, et al., 2000; GIANNINI, 2007). O conjunto dessas estruturas, associadas a rizólitos da fácies $\mathrm{AMr}$, sugere um contexto semelhante ao de dunas frontais intensamente vegetadas como principal elemento morfológico associado à deposição das fácies $\mathrm{AMb}$ e AMr.

Em algumas localidades nas proximidades de Santarém (município de Amontada), os depósitos de dunas frontais e de praia subjacentes foram entalhados por pequenos cursos d'água efêmeros, formando vales incisos com profundidades de até $2 \mathrm{~m}$.

\section{Associação de fácies de cadeias de dunas barcanóides e extensões lineares (Fácies AMf/AMz)}

Cadeias barcanóides consistem em um conjunto de dunas barcanas lateralmente coalescidas, com cristas sinuo- sas e orientação transversal ao vento principal (MARTINHO et al., 2006). Essa orientação é, em tese, responsável pelo desenvolvimento de feições como extensões lineares e cúspides com orientações perpendiculares à crista da duna (COLLINSON \& THOMPSON, 1982).

Algumas cadeias barcanóides podem se estender lateralmente de forma contínua por quilômetros e alturas de dezenas de metros. A sinuosidade da crista das ondulações imprime, nesse tipo de depósito, conjuntos de estratificações cruzadas planares tangenciais na base e estratificações cruzadas festonadas em conjuntos lenticulares côncavo-convexas. Estruturas sedimentares semelhantes são encontradas na fácies AMf, possivelmente formada em contexto paleoambiental semelhante a esse tipo de duna.

Extensões lineares são ocasionalmente vegetadas e apresentam a crista retrabalhada por rupturas de deflação eólica, geralmente associadas a cadeias barcanóides (MARTINHO, 2004; GIANNINI et al., 2011). Essas feições possuem estruturas internas semelhantes às de dunas seif, como as observadas em cadeias barcanóides ativas (MARTINHO et al., 2006), onde possuem dois sentidos predominantes de vento, ligeiramente oblíquas à crista da duna. Essa configuração resulta na construção de estratificações cruzadas planares, subtabulares a cuneiformes, apresentando superfícies de truncamento em forma de " $Z$ " (MCKEE \& TIBBITTS, 1964; MCKEE, 1982; GIANNINI et al., 2008). Os eolianitos da fácies AMz apresentam esses tipos de estruturas com corpos cuneiformes, além de mergulhos com caimentos aproximados para (WNW) quanto à linha de costa (MESQUITA et al., 2014; MESQUITA, 2015) (Figura 11). Desse modo, essa fácies poderia ser interpretada como produto de extensões lineares associadas a cadeias de dunas barcanóides pretéritas no litoral oeste do Ceará.

\section{Modelo evolutivo}

As rochas de praia das fácies AGpi são tipicamente relacionadas ao ambiente praial e possuem provável correlação a antigos níveis marinhos depositadas durante um nível relativo do mar alto. A sobreposição da associação de fácies de dunas frontais e a presença de afloramentos da fácies AGpi no interior do continente indicam um sequente comportamento progradacional da linha de costa, que culminou no desenvolvimento acelerado de cordões de dunas frontais e na cimentação dos depósitos pelo rebaixamento do nível freático. É possível, também, que o comportamento retrogradacional da costa, registrado na base da sucessão , tenha auxiliado na construção de cadeias de dunas barcanóides transgressivas sob os tabuleiros pré-litorâneos, explicando a ausência de relações de contato entre as fácies AMf e AMz com a fácies AGpi (Figura 12). 
Mesquita A. F. et al.

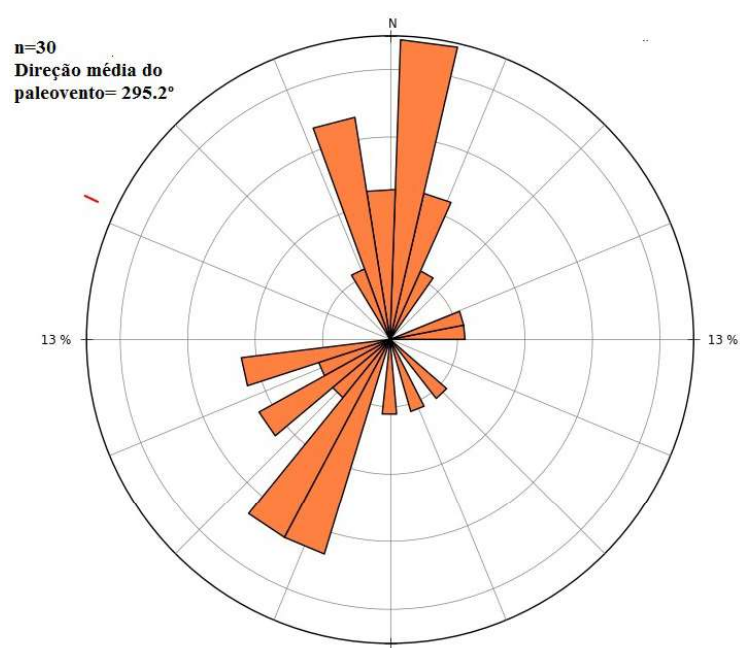

Figura 11 - Diagrama de roseta para as direções dos sets de estratificações cruzadas da fácies AMz. Observar dois principais grupos de sets de estratificações cruzadas (NW-NE e SW). As intersecções desses planos originam uma linha correspondente à crista de extensões lineares, indicando sentido de migração (WNW média de 295, $2^{\circ}$ Az). Modificado e adaptado de Vasconcelos e Barnabé (2011).

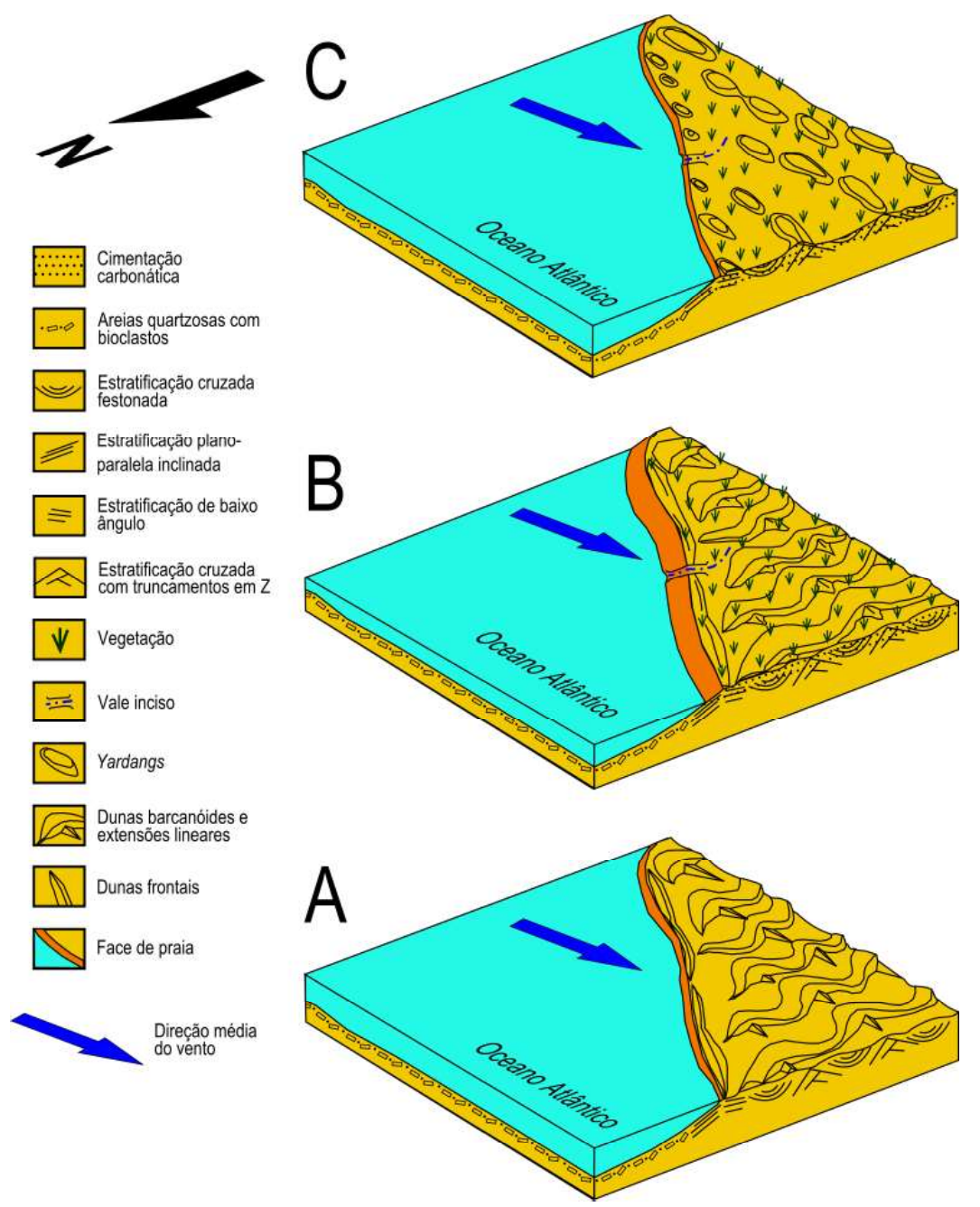

Figura 12 - Modelo de evolução geológica proposta para o setor centro leste da área de estudo. A: deposição de depósitos de praia e eólicos durante subida do nivel relativo do mar. B: estabilização do campo de dunas por diminuição do suprimento sedimentar por rebaixamento relativo do nivel do mar, com cobertura por vegetação e cimentação (eodiagenética) marinha freática a vadosa nos depósitos de face de praia, formando rochas de praia, e continental vadosa nos depósitos eólicos, formando eolianitos. Incisão fluvial. C: Abrasão eólica com formação de yardangs nos eolianitos, durante provável ascensão do nível relativo do mar (estágio atual). 
Cooper (1958), Pye \& Bowman, (1984); Giannini \& Santos (1994); Sawakuchi, (2003); Lees, (2006) e Giannini et al., (2007) sugerem que a construção de campos de dunas costeiras é, em emersão, melhor explicada em NRM (Nível relativo do mar). Em NRM baixo, os sedimentos expostos acima da amplitude de maré apresentam elevada probabilidade de serem estabilizados por processos pós-deposicionais, tais como: colonização biológica, cimentação eodiagenética e desenvolvimento de solos, desfavorecendo o retrabalhamento de sedimentos pelo vento. Além disso, em contexto de queda do nível de base, os depósitos seriam submetidos à incisão por vales fluviais, diminuindo o seu potencial de preservação. Por outro lado, esses autores argumentam que sistemas eólicos costeiros estariam melhor relacionados a elevações do NRM. Nesse contexto, a erosão costeira atua com mais intensidade, disponibilizando uma alta carga sedimentar para zona submersa da praia. $\mathrm{O}$ excesso de sedimento provoca um desequilíbrio no perfil de praia, induzindo à transferência de sedimentos para a faixa de intermaré. Sob um regime de ventos adequado, há uma remobilização de sedimentos para a faixa de supramaré, originando campos de dunas costeiros. Assim, o transporte sedimentar eólico agiria em intensidade maior do que a colonização biológica e os processos eudiagenéticos seriam insuficientes para a estabilização desses corpos sedimentares. Esse sistema foi descrito, primeiramente, por Cooper (1958), para sistemas eólicos da costa de Oregon (EUA), o qual sugere que a taxa de avanço de campos de dunas transgressivos é proporcional à taxa de erosão costeira provocada pela última subida global do nível do mar. O modelo proposto explica o aporte sedimentar necessário para o desenvolvimento de cadeias de dunas barcanóides testemunhadas pelas fácies AMf e AMz.

Como as estruturas internas da fáceis $\mathrm{AMz}$ sugerem sua gênese associada a extensões lineares, a intersecção dos principais planos dos sets de estratificações cruzadas define uma linha que representará a crista da duna, paralela à principal direção do vento e à paleodireção média de migração do campo de dunas. $\mathrm{O}$ diagrama de roseta da figura 11 apresenta dois principais grupos de sets de estratificações cruzadas para a fácies $\mathrm{AMz}$ (NW-NE e SW), sugerindo que a paleodireção de migração do campo de dunas responsáveis pela construção desses depósitos possuía um trend de NW-SE e uma direção média de $295,2^{\circ}$ azimute.
Durante o último máximo glacial (cerca de 18.000 anos), o nível máximo do oceano Atlântico permaneceu cerca de 100 metros abaixo do atual. Durante o Pleistoceno Tardio e o início do Holoceno, o nível marinho se elevou, atingindo níveis de máxima transgressão (4 $\pm 5 \mathrm{~m}$ acima do atual) entre 5.500 e 5.000 anos AP na costa atlântica meridional do Brasil (SUGUIO et al., 1985; VIEIRA, 1981; MARTIN et al., 2003; ANGULO et al., 2006; SUGUIO et al., 2013). No entanto, poucos registros de variação do nível relativo do mar foram caracterizados na costa atlântica equatorial. Dentre alguns achados na costa setentrional do Rio Grande do Norte, há o registro de rochas de praia em nível situado 1,3 $\mathrm{m}$ acima do nível médio do mar atual, com idades de radiocarbono de 5.900 anos AP, abaixo do que foi registrado na costa meridional (BEZERRA et al., 2003; CALDAS et al., 2006). Esse dado sugere comportamentos distintos entre ambas as costas no mesmo período.

Entretanto, evidências, tanto na costa do Pará e Maranhão (COHEN et al., 2005; BEHLING et al., 2001; BEHLING \& COSTA, 2001), quanto na costa cearense a oeste da área de estudo (IRION et al., 2012), sugerem que o NRM, para grande parte da porção equatorial da costa brasileira, não esteve acima do nível atual nos últimos 7.000 anos. Levando-se em consideração esse panorama, a área de estudo apresenta uma configuração anômala. A presença de níveis marinhos (rochas de praia com baixo grau de cimentação) acima da amplitude máxima de maré, por vezes com vales incisos, e a sucessão de fácies encontradas fornecem indícios de um rebaixamento do NRM no setor. Datações realizadas em eolianitos entre Acaraú e Itarema por Luminescência Opticamente Estimulada (LOE) apontaram idades de deposição desses depósitos entre 2,4 e 1,0 Ka (VASCONCELOS, 2014). Portanto, é possível considerar como idade máxima cerca de 2,5 Ka para o início da retrogradação da linha de costa e desenvolvimento desses depósitos.

Em geral, o modelo de NRM em ascensão para a geração de campos de dunas transgressivos considera $\mathrm{o}$ fundo plataformal estático. Entretanto, para o litoral oeste do Ceará, existem indícios de atividade neotectônica, possivelmente induzida por movimentações crustais desde o final do Pleistoceno no entorno do Lineamento Transbrasiliano (LTB), como anomalias positivas de relevo (soerguimentos) na plataforma continental adjacente (SILVA FILHO et al., 2007; MESQUITA, 2015). Embora as causas ainda sejam motivo de especulações, 
os depósitos sedimentares do conjunto rochas de praia/ eolianitos no setor litorâneo oeste do Ceará, especialmente entre Almofala e Flexeiras, registram um ciclo de ascensão e rebaixamento do NRM. A fase de ascensão foi responsável pelo desenvolvimento dos depósitos de praia e campos de dunas, sucedida por eodiagênese, e pela formação de rochas de praia e eolianitos na fase de submersão do nível relativo do mar (Figura 12).

\section{Considerações finais}

Os eolianitos representam uma unidade litoestratigráfica holocênica bastante representativa no litoral leste do Ceará. Foram aqui apresentadas cinco unidades faciológicas que compõem três principais associações de fácies: i) associação de fácies de faixa de praia composta pela fácie AGpi (arenito grosso com níveis conglomeráticos e estratificação plano-paralela inclinada), ii) associação de fácies de dunas frontais compostas pela fácies $\mathrm{AMb}$ (arenito médio com estratificações cruzadas de baixo ângulo) e AMr (arenito médio com estratificações cruzadas de baixo ângulo obliteradas por rizoconcreções) e iii) associação de fácies de dunas barcanóides e extensões lineares representadas pelas fácies $\mathrm{AMf}$ (Arenito médio com estratificação cruzada festonada) e AMz (arenito médio com estratificação cruzada com superfície de truncamento em " $Z$ ").

Acredita-se que o desenvolvimento de rochas de praia e eolianitos no litoral oeste do Ceará tiveram forte influência por flutuações relativas ao nível do mar, no Holoceno, ocorridas em dois principais estágios. O primeiro estágio é caracterizado por NRM alto responsável pela deposição de rochas de praia, com cimentação vadosa marinha próxima da interface freática e pela construção de campos de dunas. Nesse estágio, a maior remobilização e oferta de sedimentos (siliciclásticos e carbonáticos) para o pós-praia resultou na construção de dunas frontais e campos de dunas transgressivas compostas por dunas barcanóides associadas a extensões lineares.

O segundo estágio é caracterizado por um NRM em submersão. Essa fase foi responsável pelos eventos eodiagenéticos de cimentação presentes no topo da fácies AGpi e das demais fácies de eolianitos compostos pela transição da cimentação marinha freática, base da sequência, para cimentação vadosa com influência meteórica, topo da sequência, possivelmente induzida pelo rebaixamento no nível freático. A presença de afloramentos da fácies AGpi no interior do continente corroboram com essa hipótese.

As direções de paleovento indicam que as cristas de extensões lineares se formaram em direções subparalelas, aproximadamente, a WNW, provável trend de migração desses campos de dunas. O suprimento de sedimentos para o desenvolvimento de campos de dunas ocorreu, proporcionalmente, à taxa de elevação do NRM, de forma que o subsequente rebaixamento do NRM favoreceu à redução na disponibilidade de sedimentos para construção de campos de dunas, diminuindo sua velocidade de migração. Uma vez cimentados e expostos, esses pacotes de rochas foram submetidos a processos de entalhamento por cursos fluviais e à ação dos ventos, formando vales incisos e yardangs, respectivamente.

Esse panorama é relacionado ao setor Almofala-Flexeiras, a leste da terminação do Lineamento Transbrasiliano na margem continental ao largo do Ceará. A influência neotectônica na área de estudo ainda deve ser melhor entendida, somando-se ao comportamento eustático para a compreensão da variação do NRM local.

\section{Agradecimentos}

Este trabalho constitui parte da Dissertação de Mestrado do primeiro autor, no Programa de Pós-graduação em Geologia da Universidade Federal do Ceará (UFC). Agradecemos a CAPES pelo auxílio financeiro relacionado a bolsas de estudos, bem como à UFC pelo apoio institucional, além dos professores Dr. Daniel Rodrigues do Nascimento Junior e Dr. Kenitiro Suguio, por sugestões e críticas pertinentes. Os autores também agradecem ao INCT-Estudos tectônicos e ao projeto "Lineamento Transbrasiliano: Origem, Evolução e Influência na Sedimentação de Bacias Fanerozóicas", ambos coordenados pelo Dr. R. A. Fuck (UnB), pelo auxílio aos trabalhos de campo.

\section{Referências Bibliográficas}

AGUIAR, P.F; EL-ROBRINI, M; FREIRE, G.S.S; CARVALHO, R.G. Morfodinâmica de praias dominadas por mesomarés na Planície Arenosa de Almofala, NW do Ceará (Brasil). Pesquisas em Geociências, v. 40, n. 1, p. 61-73, 2013.

ÂNGULO, R. J; LESSA, G. C; SOUZA, M.C. A critical review of mid- to Late-Holocene sea level fluctuations on the eastern 
Brazilian coastline. Quaternary Science Reviews, v. 25, n. 5-6, p. $486-506,2006$.

ARAI, M.A. Grande elevação eustática do mioceno e sua influência na origem do Grupo Barreiras. Geologia USP- Série Científica, v. 6, n. 2, p. 1-6, 2006.

BEHLING, H; COHEN, M.C.L, LARA, R.J. Studies on Holocene mangrove ecosystem dynamics of the Bragança Peninsula in north-eastern Pará, Brazil. Paleogeography, Paleoclimatology, Paleoecology, v. 167, p. 225-242, 2001.

BEHLING, H; COSTA, M.L. Holocene vegetational and coastal evironmental changes from the Lago Crispim record in notheastern Pará State, eastern Amazonia. Review of Paleobotany and Palynology, v. 114, p. 145-155, 2001.

BEZERRA, F.H; VITA-FINZI, C. How active is a passive margin? Paleoseismicity in Northeastern Brasil. Geology, v. 28, n. 7, p. 591-594, 2000.

BEZERRA, F.H.R.; BARRETO, A.M.F.; SUGUIO, K. Holocene sea-level history on the Rio Grande do Norte State coast, Brazil. Marine Geology, v. 196, n. 1-2, p. 73-89, 2003.

BEZERRA, F.H.R; FONSECA, V.P; VITA-FINZI, C; LIMAFLIHO, F.P; SAADI, A. Liquefaction-induced structures in Quaternary alluvial gravels and gravelly sediments, NE Brazil. Engineering Geology, v. 76, p. 91-208, 2005.

BEZERRA, L.J.C. Caracterização dos Tabuleiros Prélitorâneos do Estado do Ceará. (Dissertação de Mestrado em Ciências Marinhas Tropicais), Universidade Federal do Ceará, Fortaleza, 132 p., 2009.

BRANDÃO, R. L. Diagnóstico geoambiental e os principais problemas de ocupação do meio físico da região Metropolitana de Fortaleza. Fortaleza: CPRM, 1995, 105p.

BRISTOW, C.S. The structure and development of foredunes on a locally prograding coast: Insights from ground-penetrating radar surveys, Norfolk, UK. Sedimentology, v. 47, p. 923-944, 2000.

CALDAS, L.H.O.; STATTEGGER, K., VITAL, H. Holocene sea-level history: Evidence from coastal sediments of the northern Rio Grande do Norte coast, NE Brazil. Marine Geology, v. 228, n. 1-4, p. 39-53, 2006.

CARVALHO, A.M; CLAUDINO-SALES, V; MAIA, L.P; CASTRO, J.W.A. Eolianitos de Flexeiras/Mundaú, Costa Noroeste do Estado do Ceará, Brasil. In: WINGE, M. SCHOBBENHAUS, C.; SOUZA, C.R.G.; FERNANDES, A.C.S.; QUEIROZ, E.T.; BERBERT- BORN, M.; CAMPOS, D. A. (Org.). Sítios Geológicos e Paleontológicos do Brasil.
Brasília: CPRM, 2008, p. 122 -130.

CLAUDINO-SALES, V. Cenários Litorâneos: Lagoa do Papicu, Natureza e Ambiente na cidade de Fortaleza-CE. (Dissertação de Mestrado em Geografia), Universidade de São Paulo, São Paulo, 132 p., 1993.

Claudino-SAles, V., MAIA, L. P., PEulvast, J. P. Pequenas Barreiras no Estado do Ceará, Nordeste do Brasil. In: Simpósio Nacional de Geomorfologia, 6, 2006, Goiânia Anais..., 2006.

COHEN, M.C.L; BEHLING, H; LARA, R.J. Amazonian mangrove dynamics during the last millennium: The relative sea-level and the Little Ice Age. Review of Palaeobotany and Palynology, v. 136, p. 93-108, 2005.

COLlinsON, J.D; THOMPSON, D.B. Sedimentary Structures. London: George Allen e Unwin, 1982, 187 p.

COOPER, W.S. The coastal sand dunes of Oregon and Washington. Tulsa: Geological Society America (Memoir, 72), $1958,169 \mathrm{p}$.

DHN - Diretoria de Hidrografia e Navegação. Tábua de marés. Disponível em: <http://www.mar.mil.br/dhn/chm/tabuas/index. htm>. Acesso em: 15/05/2012.

FERREIRA JR., A.V; ARAÚJO, T.C.M; VIEIRA, M.M., NEUMANN, V.H.; GREGÓRIO, M.N. Petrologia dos arenitos de praia (Beachrocks) na Costa Central de Pernambuco. Geociências, v. 4, n. 30, p. 545-559, 2011.

GIANNINI, P.C.F.; SANTOS, E.R. Padrões de variação espacial e temporal na morfologia de dunas de orla costeira no centrosul catarinense. Boletim Paranaense de Geociências, v. 42, p. 73-96, 1994.

GIANNINI, P.C.F. Sistemas deposicionais eólicos no Quatenário costeiro do Brasil. (Tese de Livre Docência), Universidade de São Paulo, São Paulo, 200 p., 2007.

GIANNINI, P.C.F.; SAWAKUCHI, A.O.; MARTINHO, C.T.; TATUMI, S.H. Eolian depositional episodes controlled by Late Quaternary relative sea level changes on the Imbituba-Laguna coastal zone (southern Brazil). Marine Geology, v. 237, p. 143-168, 2007.

GIANNINI, P.C.F; ASSINE,M.L; SAWAKUCHI, A. O. Ambientes eólicos. In: PEDREIRA, A.J; ARAGÃO, M.A.N.F; MAGAlHÃES, A.J. (Org.). Ambientes de sedimentação siliciclástica do Brasil. São Paulo: Beca, 2008, p. 72-101.

GIANNINI, P.C.F.; SAWAKUCHI, A.O.; MARTINHO, C.T.; GUEDES, C.C.F.; NASCIMENTO JR., D.R.; TANAKA, A.P.B.; 
MENDES, V.R.; ZULAR, A.; ANDRADE, H.A.A.; FORNARI, M. Classificação e dinâmica de feições eólicas costeiras: um modelo sistêmico baseado em exemplos brasileiros. In: Congresso Brasileiro de estudos do Quaternário, 13, 2011, Búzios. Anais..., 2011.

HESP, P.A. Morphodynamics of incipient foredunes in NSW, Austrália. In: In: BROOKFIELD, M.E.; AHLBRANDT, T.S.(Org.). Eolian Sediments and Processes. Amsterdam: Elsevier, 1983, p. 325-342.

HESP, P.A. Morphology, dynamics and internal stratification of some established foredunes en southeast Austrália. Sedimentary Geology, v. 55, p. 17-41, 1988.

HESP. P.A. Foredunes and blowouts: initiation, geomorphology and dynamics. Geomorphology, v. 48, n. 1, p. 245-268, 2002.

HESP, P. A., MAIA, L. P., CLAUDINO-SALES, V. The Holocene Barriers of Maranhão, Piauí and Ceará States, Northeastern Brazil. In: DILLENBURG, S.R.; HESP, P.A., (Org.). Geology and Geomorphology of Holocene Coastal Barriers of Brazil. Berlin: Heidelberg, Springer, 2009, p. 325-343.

HESP, P.A. Conceptual models of the evolution of transgressive dune field systems. Geomorphology, v. 199, p 138-149, 2013.

HUNTER, R.E. Basic types of stratification in small eolian dunes. Sedimentology, v. 24, p. 361-387, 1977.

IRION, G; MORAIS, J.O; BUNGENSTOCK, F. Holocene and Pleistocene sea-level indicators at the coast of Jericoacoara, Ceará, NE Brazil. Quaternary Research, v. 77, p. 251-257, 2012.

KLAPPA, C.P. Rhizoliths in terrestrial carbonates: classification, recognition, genesis and significance. Sedimentology, v. 27, p. 613-629, 1980.

LEES, B. Timing and formation of coastal dunes in northern and eastern Australia. Journal of Coastal Research, v. 22, n. 1, p. 78-89, 2006.

LONGMAN, M.W. Carbonate diagenetic textures from nearsurface diagenetic environments. AAPG Bulletin, v. 64, p. 461-487, 1980.

MAIA, L.P. Procesos costeros y balance sedimentario a lo largo de Fortaleza (NE-Brasil): Implicaciones para una gestión adecuada de la zona litoral. (Tesis de Doctorado en Geología), Universidad de Barcelona, Barcelona, 198 p., 1998.

MARIA, F.S. Diagnostico geoambiental da Bacia do Litoral no Ceará. Mercator - Revista de Geografia da UFC, v .11, n. 6, p. 107-116, 2007.
MARTIN, L., DOMINGUEZ, J.M.L.; BITTENCOURT, A.C.S.P. Fluctuating Holocene sea-levels in eastern and southeastern Brazil: evidence from multiple fossil and geometric indicators. Journal Coast Research, v. 19, n. 1, p. 101-124, 2003.

MARTINHO, C.T. Morfodinâmica e Sedimentologia de Campos de Dunas Transgressivos da Região de JaguarunaImbituba, Santa Catarina. (Dissertação de Mestrado em Geoquímica e Geotectônica), Universidade de São Paulo, São Paulo, 108p., 2004.

MARTINHO, C.T; GIANNINI, P.C.F; SAWAKUCHI, A.O; HESP, P.A. Morphological and depositional facies of transgressive dunefields in the Imbituba-Jaguaruna region, Santa Catarina State, Southem Brazil. Jornal of Coastal Research, Especial issue, v. 39, p. 673-677, 2006.

MCKEE, E.D; TIBBITTS JR., G.C. Primary structures of a seif dune and associated deposits in Libya. Journal of Sedimentary Petrology, v. 34, n. 1, p. 5-1, 1964.

MCKEE, E.D. Sedimentary structures in dunes of Namib Desert, South West Africa. Washington: Geological Society of America, 1982, $188 \mathrm{p}$.

MEYERS, J.H. Marine vadose beachrock cementation by cryptocrystalline magnesian calcite- Maui, Hawaii. Journal of Sedimentary Petrology, v. 57, p. 558-570, 1987

MEIRELES, A.J.A., ARRUDA, M.G.C., GORAYEB, A.P.R.L. Integração dos indicadores geoambientais de flutuação do nível relativo do mar e de mudanças climáticas no litoral cearense. Mercator - Revista de Geografia da UFC, v. 8, p. 109-134, 2005

MESQUITA, A.F. Eolianitos e beachrocks no litoral oeste do Ceará: significado sedimentológico e neotectônico. (Dissertação de Mestrado em Geologia), Universidade Federal do Ceará, Fortaleza, 81p., 2015.

MESQUITA, A.F; LIMA, G.S; SILVA FILHO, W.F; DUARTE, C.R. Assinaturas espectrais em depósitos eólicos litorâneos da Praia de Caetanos (Itapipoca-CE). Revista de Geologia - UFC, v. 27, n. 2, p. 101-110, 2014.

MESQUITA, A.F.; SILVA, F.E.Y. Faciologia e evolução quaternária dos eolianitos da faixa costeira entre os municípios de Amontada e Acaraú, litoral oeste do Ceará. 2012, (Relatório de Graduação em Geologia), Universidade Federal do Ceará, Fortaleza, 88 p., 2012.

MIALL, A.D. Principles of sedimentary basin analysis. New York: Springer-Verlag, 1999, 661 p.

MOUNTNEY, N.P.; JAGGER, A. Stratigraphic evolution of a 
wet aeolian system: The Permian Cedar Mesa Sandstone, SE Utah. Sedimentology, v. 51, p. 713-743, 2004.

OLSON, J.S.; VAN DER MAAREL, E. Coastal dunes in Europe: a global view. In: VAN DER MAAREL, E., JUNGERIUS, P.D; VISSER, J. (Org.). Perspectives in coastal dune management. SPB Academic Publishing, 1989, p 3-32.

PAULA, N.D.E; YAMANOTO, J.K; TOGNON, A.A. Seções delgadas de solo: método de impregnação com resina plástica Araldite. Boletim IG-USP - Publicação especial (Jornada Científica), v. 9, p. 193-196, 1991.

PEREIRA, M.M.V.; ROS, L.F. Cementation patterns and genetic implications of Holocene beachrocks from Northeastern Brazil. Sedimentary Geology, v. 192, n. 3-4, p. 207-230, 2006.

PYE, K. Coastal dunes. Progress in Physical Geography, v. 7, p. 531-546, 1983.

PYE, K.; BOWMAN, G.M. The Holocene marine transgression as a forcing function on episodic dune activity on the Eastern Australian Coast. In: THOM, B.G. (Org.), Coastal Geomorphology in Australia. Sydney: Academic Press, 1984, p. 115-127.

SAWAKUCHI, A.O. Sistemas deposicionais eólicos quaternários na Costa Centro-Sul Catarinense: Relações com o nível do mar. (Dissertação de Mestrado em Geoquímica e Geotectônica), Universidade de São Paulo, São Paulo, 86 p., 2003.

SELLEY, R.C. Ancient Sedimentary Environments. Cornell: Cornell University Press, 1970, 237 p.

SILVA FILHO, W.F; CASTRO, D.L.; CORRÊA, I.C.S.; FREIRE, G.S.S. Estruturas rasas na margem equatorial ao largo do nordeste brasileiro, Estado do Ceará: Análise de relevo e anomalias gravimétricas residuais. Revista Brasileira de Geofísica, v. 25, n. 1, p. 65-77, 2007.

SOARES, A.M.L. Zoneamento geoambiental do município de Beberibe. (Dissertação de Mestrado em Geografia), Universidade Estadual do Ceará, Fortaleza, 100 p. 1998.

SUGUIO, K.; MARTIN, L.; BITTENCOURT, A.C.S.P.; DOMINGUEZ, J.M.L.; FLEXOR, J.M.; DE AZEVEDO, A.E.G.
Flutuações do nível relativo do mar durante o Quaternário Superior ao longo do litoral brasileiro e suas implicações na sedimentação costeira. Revista Brasileira de Geociências, v. 15, p. 273-286, 1985.

SUGUIO, K.; BARRETO, A.M.F.; DE OLIVEIRA, P.E; BEZERRA, F.H.R., SANTIAGO- HUSSEIN, M.C. Indicators of Holocene sea level changes along the coast of the Pernambuco and Paraíba, Brazil. Geologia USP- Série Científica, v. 13, n. 4, p. 141-152, 2013.

TSOAR, H; LEVIN, N; PORAT, N; MAIA, L. P; HERRMANN, H. J; TATUMI, S.H; CLAUDINO-SALES, V. The effect of climate change on the mobility and stability of coastal sand dunes in Ceará State (NE Brazil). Quaternary Research, v. 71, p 217-226, 2009.

TUCKER, M.E. Sedimentary Petrology: an introduction of the origin of sedimentary rocks. London: Blackwell Science, $1991,260 \mathrm{p}$.

VASCONCELOS, D.L.; BARNABÉ, H.E.P. Beachrocks e eolianitos no litoral oeste do estado do Ceará: aspectos faciológicos e genéticos. (Relatório de Graduação em Geologia), Universidade Federal do Ceará, Fortaleza, 84 p., 2011.

VASCONCELOS, D.L. Indicadores do nível relativo do mar e evolução costeira durante o Holoceno tardio no Litoral Oeste do Ceará, NE do Brasil. (Dissertação de Mestrado em Geodinâmica e Geofísica), Universidade Federal do Rio Grande do Norte, Natal, 86 p., 2014.

VIEIRA, M.M. Aspectos sedimentológicos e petrológicos dos beachrocks do Rio Grande do Norte. (Tese de Doutorado em Geociências), Universidade Federal do Rio Grande do Sul, Porto Alegre, 243 p., 2005.

VIEIRA, M.M.; ROS, L.M.; BEZERRA, F.H.R. Lithofaciology and palaeoenvironmental analysis of Holocene beachrocks in northeastern Brazil. Journal of Coastal Research, v. 23, p. 1535-1548, 2007.

VIEIRA, P.C. Variações do nível marinho. Alterações eustáticas no Quaternário. Revista do Instituto Geológico, v. 2, n. 1, p. 39-57, 1981. 